\title{
Doubled Haploids in Rice Improvement: Approaches, Applications, and Future Prospects
}

\author{
Sanghamitra Samantaray, Jauhar Ali, Katrina L. C. Nicolas, \\ Jawahar Lal Katara, Ram Lakhan Verma, C. Parameswaran, B. N. Devanna, \\ Awadhesh Kumar, Byomkesh Dash, and Sudhansu Sekhar Bhuyan
}

\begin{abstract}
Exploitation of biotechnological tools in conventional breeding strategies is the need of the hour for overcoming limitations in rice production and productivity. In addition, improvement in quantity and quality along with resistance to climatic and disease stress in rice require immediate attention. Anther culture has proven its efficiency by instantaneously fixing homozygosity through diploidization of regenerated haploid plants. Therefore, androgenesis provides an efficient platform for developing inbred lines in a short period of time. Although anther culture shows its efficiency in speeding up breeding in several crop species, including rice, associated limitations still prevent the exploitation of its optimum potential. Although anther culture is well exploited in japonica rice breeding, its application in indica rice is limited because of inherent recalcitrant genetic backgrounds. The success of anther culture is determined by several factors that limit the efficiency of androgenesis. Identified constraints are early anther necrosis, poor-callus response, and proliferation, and low green-plant regeneration, along with the most frustrating albinism associated with indica rice, which has been considerably clarified. This chapter details the method of androgenesis and scope for improving the applicability of anther culture producing doubled haploids of rice in order to use it as a complementary tool for precision breeding.
\end{abstract}

Keywords Androgenesis · Doubled haploid · Callus · Regeneration · Anther culture

\footnotetext{
S. Samantaray $(\varangle) \cdot$ J. L. Katara $\cdot$ R. L. Verma $\cdot$ C. Parameswaran · B. N. Devanna

A. Kumar · B. Dash · S. S. Bhuyan

ICAR-National Rice Research Institute, Cuttack, Odisha, India
}

J. Ali · K. L. C. Nicolas

IRRI, Metro Manila, Philippines 


\section{Introduction}

Doubled-haploid breeding through anther culture has emerged as an exciting and powerful tool, and a convenient alternative to conventional techniques for crop improvement (Purwoko et al. 2010). Doubled haploids have several advantages, such as shortening the breeding cycle by immediate fixation of homozygosity, offering high-selection efficiency, widening genetic variability through the production of gametoclonal variants, and expressing desirable recessive genes suitable for breeding (Devaux and Pickering 2005). Despite all the advantages DH technology offers in several crops, it has not been put to use in rice to sufficient extent in order to take maximum advantage, even though more than half of the world's population depends on rice for consumption as staple food. Further, the development of high-yielding rice cultivars is urgently needed to meet the demand of the increasing population and the challenges of a changing climate since cultivar development is a lengthy and time-consuming process. However, anther culture has been exploited to develop several varieties and improved breeding lines, mostly in japonica cultivars (Grewal et al. 2011). Contrastingly, this technique has poor implications in indica rice cultivars owing to poor-androgenic response. In addition, early anther necrosis, poor-callus proliferation, and albino-plant regeneration are some of the major problems encountered in the case of indica rice at the time of androgenesis, which needs vast improvement. Hence, attempts are being made to overcome low-anther culturability by evaluating several key factors involved in affecting the success of anther culture (Trejo-Tapia et al. 2002; Jacquard et al. 2006). DH technology integrated with phenomics and genomics could accelerate cultivar development and economize plant-breeding operations.

Several approaches in the production of DHs were developed, for which in vitro culture was found to be the most efficient and simplest technique. It is being used to produce haploids/doubled haploids in several crops. The two commonly used in vitro methods for DH production are gynogenesis and androgenesis. However, androgenesis shows its effectiveness and applicability in producing haploids and DHs in numerous cereals (Forster et al. 2007). To alleviate the problems associated with indica rice $\mathrm{DH}$ breeding, manipulation of the limiting factors related to androgenesis is required to achieve a successful protocol for effective exploitation.

This chapter deals with insights into the practical aspects of anther culture technique for it to be fully exploited for improving rice breeding.

\section{Status of Doubled-Haploid Research in the Success of Indica Rice Anther Culture}

The past and current status of research highlights the usefulness of DH technology in rice improvement. The discovery of haploids in plants led to the use of DH technology in plant breeding. Although there are different methods to generate 
haploids, they are usually accompanied by chromosome doubling. In general, in vitro methods were found to be the most pertinent in developing haploids and DHs, for which androgenesis shows its effectiveness and applicability in numerous cereals, including rice. These systems allow completely homozygous lines to be developed from heterozygous parents in a single generation.

The first naturally occurring haploids were reported by Blakeslee et al. (1922) in jimson weed (Datura stramonium L.) and thereafter natural haploids were documented in several other species. However, the relevance of DHs came into prominence only when Guha and Maheshwari $(1964,1966)$ reported a breakthrough in the production of haploids from anther culture of Datura innoxia (Mill.). Further, their research revolutionized the use of DH technology in plant breeding worldwide. Subsequently, this haploid discovery by anther culture provided several opportunities for applying this technique in crop improvement programs. In rice, the first report on producing haploids through anther culture came from Niizeki and Oono (1968). Subsequently, the doubled-haploidy approach coupled with conventional breeding led to the development of several rice varieties for pest and disease resistance, high yield, and good-quality grains in many countries. Furthermore, anther culture could facilitate other biotechnological approaches such as gene transformation technology and the identification of QTLs.

Despite all the advantages DH technology offers, it has not been put to use in indica rice to a great extent for maximizing its advantage. This is mostly because of the lack in expertise and the variable response of different genotypes under in vitro culture. Although the androgenic response to japonica-subspecies has led to the release of many varieties, the potential of anther culture for indica rice breeding is not fully exploited, in spite of the release of a salt-tolerant indica variety through anther culture (Senadhira et al. 2002). Early anther necrosis, poor-callus proliferation, and albino-plant regeneration are some of the problems encountered in indica rice at the time of androgenesis, which are researchable concerns. Several determining factors associated with poor-androgenic response were also addressed to obtain success in rice anther culture. Although one-step androgenesis (somatic embryogenesis) is cost-effective vis-à-vis two-step organogenesis, the latter was widely adopted because of its responsiveness in rice.

Physiology of the donor plant is an important contributory factor for the success of rice anther culture. Anthers of panicles collected from field-grown plants have been decided better in their anther culture response than anthers collected from pot plants placed in the greenhouse or near the field (Veeraraghavan 2007). Second, the microspore stage is considered as an important factor for androgenic response. An easily observable morphological trait of the plant that shows good correlation with the pollen development stage is used as a guide to identify the required stage of the microspore (Nurhasanah et al. 2016). Usually, the distance between the collar of the flag leaf and the ligule of the penultimate leaf of the tiller serves as a reliable guide to anther maturity. The most suitable stage of microspore development has been described as the late uninucleate to early binucleate stage. However, the appropriate microspore stage for effective androgenic response was reported as early as miduninucleate stage (Fig. 1a). 


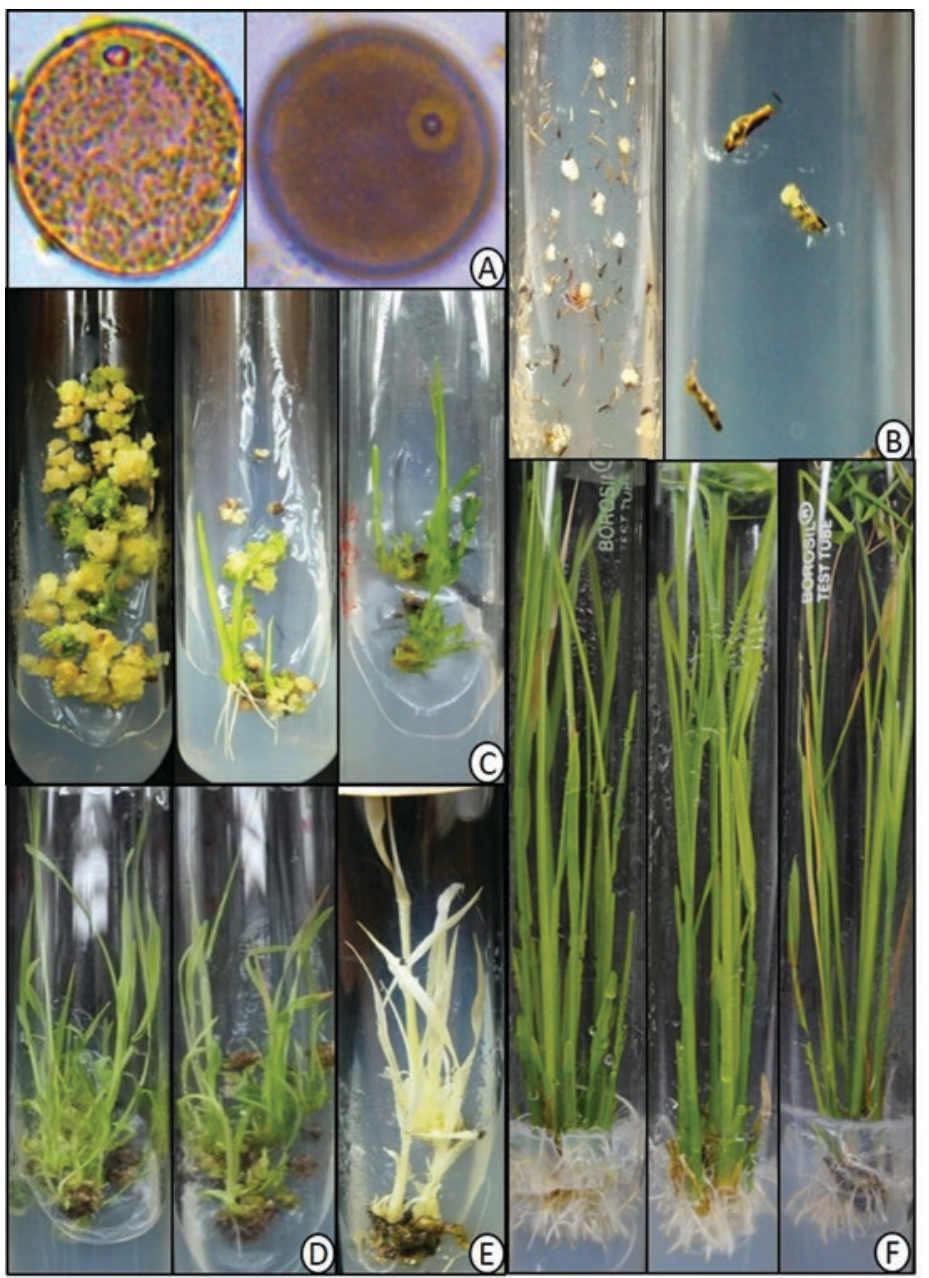

Fig. 1 Androgenesis in rice hybrids (CRHR32 and BS6444G). (a) Early to mid-uninucleate stages of microspore; (b) callus induction; (c) green spot indicating shoot bud emergence; (d) shoot elongation; (e) albino shoot regeneration; (f) root to microshoots

A wide range of chemical and physical factors influences androgenesis in vitro. The most widely used pretreatment for androgenesis is low-temperature shock with appropriate duration. Mishra et al. (2013) assessed the influence of cold pretreatment at $10^{\circ} \mathrm{C}$ for 7-9 days on the anther culture response of Rajalaxmi (CRHR 5) and Ajay (CRHR 7), which showed a positive influence on callus induction frequency irrespective of the media and plant growth regulators (PGRs) employed; prolonged treatment over the optimum duration proved to be inhibitory for androgenesis. However, cold treatment $\left(10^{\circ} \mathrm{C}\right)$ for 8 days was found to be effective for callus induction and green-plant regeneration in a popular indica rice hybrid, BS6444G 
(Naik et al. 2017). In addition, 2 days of preincubation period at $10{ }^{\circ} \mathrm{C}$ was quite interesting for the success of androgenesis in a long-duration indica rice hybrid (Rout et al. 2016).

The most commonly used basal media for anther culture are N6, MS, B5, and Potato-2 medium. Subsequently, several media (MSN, SK1, He2, and RZ) were developed from N6 media by modifying the nitrogen rates and sources, carbon content and sources, and changes in vitamins and their concentrations, which were found to be encouraging for anther response in rice. N6 media were found to induce maximum callusing in Taraori Basmati (Grewal et al. 2006). Min et al. (2016) found out the best media for androgenesis in the generation of DHs from $\mathrm{F}_{1} \mathrm{~s}$ of two intervarietal crosses in terms of callusing (N6) and shoot regeneration ( $1 / 2 \mathrm{MS})$ after a trial with 16 different media. However, two basal media, such as N6 and MS, were found to be effective for callusing and green-shoot regeneration, respectively, in indica rice hybrids (Rout et al. 2016; Naik et al. 2017).

Considering the importance of plant growth regulators in tissue culture, the effects of different PGRs were investigated for androgenesis. Even though 2,4-D has proven to be a potent auxin for callus induction from cultured anthers, medium with lower 2,4-D rates was found to be more effective for the regeneration ability of calli induced in indica rice than higher 2,4-D rates (Fig. 1b). The calli developed green spots in 7-10 days after transfer to media supplemented with NAA $(0.5 \mathrm{mg} / \mathrm{L})$, BAP (1.0 mg/L), and $\mathrm{Kn}(1.0 \mathrm{mg} / \mathrm{L})$, which adequately supported green-plant regeneration from subcultured calli (Fig. 1c, d). The type and concentration of auxins seem to determine the pathway of microspore development with 2,4-D inducing callus formation and IAA and NAA promoting direct embryogenesis (Ball et al. 1993). The 2,4-D was found effective for callus response while the combinations of NAA, Kn, and BAP showed shoot regeneration in the generation of DHs from $\mathrm{F}_{1} \mathrm{~s}$ of two intervarietal crosses and hybrid rice (Min et al. 2016; Rout et al. 2016; Naik et al. 2017).

The nitrogen composition supplied in the form of nitrate and/or ammonium ions in culture media plays a significant role in androgenesis. The ratio of nitrate $\left(\mathrm{NO}_{3}{ }^{-}\right)$: ammonium $\left(\mathrm{NH}_{4}^{+}\right)$has been observed to be an important determinant for the success of anther culture as well as for the in vitro induction of embryogenic calli in indica rice (Grimes and Hodges 1990). Ivanova and Van Staden (2009) investigated the elimination of total nitrogen in media, resulting in limited ability of proliferation and shoot growth, but higher ability was observed in media containing $\mathrm{NO}_{3}{ }^{-}$as the only sole nitrogen source, whereas replacing the $\mathrm{NH}_{4}{ }^{+}$with $\mathrm{NO}_{3}{ }^{-}$decreased the rate of hyperhydricity. Herath et al. (2007) proved that the frequency of callus induction was improved by modifying three different media (N6, B5, and Miller) with one-half the rate of $\mathrm{NH}_{4}{ }^{+}$and double the rate of $\mathrm{KNO}_{3}$ nitrogen.

A carbohydrate source is essential for androgenesis because of the osmotic and nutritional effects. Naik et al. (2017) aptly demonstrated the superiority of maltose over sucrose as the carbon source in rice anther culture for callusing. Replacing sucrose $(146 \mathrm{mM})$ with maltose $(146 \mathrm{mM})$ in the callus induction medium had a significant positive effect on anther response in both indica and japonica types, with 
a greater effect on indica rice. With respect to the effect of light quality on anther culture, the embryogenic induction of microspores is inhibited by high-intensity white light, whereas darkness or low-intensity white light is found encouraging (Bjørnstad et al. 1989). The incubation of anthers continuously in the dark has, on occasion, been found to be essential.

Most in vitro morphogenic responses are genotype-dependent. In general, indica rice cultivars exhibit poor-androgenic response vis-à-vis japonica ones. Even among the indica cultivars, a considerable variation in microspore callusing and green-shoot regeneration has been observed (Rout et al. 2016; Naik et al. 2017). The highest callus-responsive cultivars often show the best regeneration frequency and the best responsive genotypes to callusing exhibit low-regeneration ability. Therefore, selection of a single step, either callus improvement or shoot regeneration alone, may not help in establishing an effective androgenic method. It is rather important to identify genotypes carrying the two traits for overall improvement in anther culture efficiency.

The occurrence of a large proportion of albinos among the regenerated plants following anther culture is the most frustrating feature of androgenesis and this remains a formidable obstacle for application to rice breeding. The frequency of albinos can vary from $5 \%$ to $100 \%$ (Talebi et al. 2007). Indica rice cultivars are more prone to this problem than japonica cultivars. Several factors, including pretreatment conditions and culture medium, affect the frequency of albinos, which could be considerably decreased by shortening the culture period (Asaduzzaman et al. 2003). The presence of large-scale deletions in some plastid genomes of the albino haploid plants derived from anther culture of japonica $\times$ indica hybrids and absence of such deletions in green regenerants (Yamagishi 2002) appeared to suggest a role for the plastid genome in determining the albino phenotype. The albinos (60-100\%) in the regeneration culture proved to be detrimental for optimizing an androgenic response (Fig. 1e). Therefore, ICAR-NRRI, India, attempted to develop a protocol for the suppression of albinism, which led to standardization of a $100 \%$ albino-free shoot regeneration method in indica rice (patent filed 1355/KOL/2015 titled "Method for albino-free shoot regeneration in rice through anther culture").

The well-developed shoots were transferred to MS media supplemented with $2.0 \mathrm{mg} / \mathrm{L} \mathrm{NAA}, 0.5 \mathrm{mg} / \mathrm{L} \mathrm{Kn}$, and $5 \%$ sucrose for rooting. Root induction starts 7 days after transfer, followed by profuse rooting after 4 weeks of culture (Fig. 1f).

\section{Diploidization of Haploid Genomes}

Haploids can be diploidized (duplication of chromosomes) to produce homozygous plants. There are two approaches for haploidy diploidization. 


\subsection{Artificial Genome Doubling}

Artificial genome doubling is the most popular method applied for doubling genomes in large-scale DH production. Colchicine, an antimicrotubule drug, has been widely used and is the most effective genome-doubling agent. Colchicine duplicates the genome by binding to tubulins and inhibits microtubule polymerization (Kleiber et al. 2012; Prasanna et al. 2012; Weber 2014). However, colchicine is highly toxic, which is not only potentially carcinogenic but also hazardous to the environment (Melchinger et al. 2016). The effects of other agents with lower toxicity on chromosome doubling, such as amiprophos-methyl (APM), oryzalin, pronamide, and trifluralin (all of which are herbicides), have been reported (Wan et al. 1991; Häntzschel and Weber 2010; Murovec and Bohanec 2012).

\subsection{Spontaneous Genome Doubling}

Spontaneous genome doubling is cost-effective and has been reported in several cereals, including rice. The frequency of spontaneous genome doubling is reported to be 50-60\% in rice (Seguí-Simarro and Nuez 2008). However, interestingly, a recent report on rice hybrid BS6444G showed 90-99\% spontaneous doubling (Naik et al. 2017). The doubling rate fluctuates extremely among genotypes (Chalyk 1994; Kleiber et al. 2012). Endomitosis is one of the phenomena of doubling the number of chromosomes without division of the nucleus. The haploid cells in general are unstable in culture, with a tendency to undergo endomitosis. This property of haploid cells is exploited for diploidization to produce homozygous plants. The procedure involves growing a small segment of haploid plant stem in a suitable medium supplemented with growth regulators (auxin and cytokinin). This induces callus formation followed by differentiation. During callus growth, chromosomal doubling occurs by endomitosis. This results in the production of diploid homozygous cells and ultimately true homozygous plants.

\section{Characterization of Regenerants: Ploidy Analysis}

After a successful haploid induction and the regeneration procedure, evaluation of regenerants is needed to distinguish doubled haploids from redundant heterozygous diploids grown in the net house (Fig. 2a). During the production of homozygous lines, various undesired heterozygous plantlets can be obtained. In anther culture, these plants can be regenerated from the somatic tissue of inoculated plant organs such as anther wall cells, tapetum, and filaments. Reliable and fast selection of regenerants is therefore necessary before further employment of putative haploids and doubled haploids. 


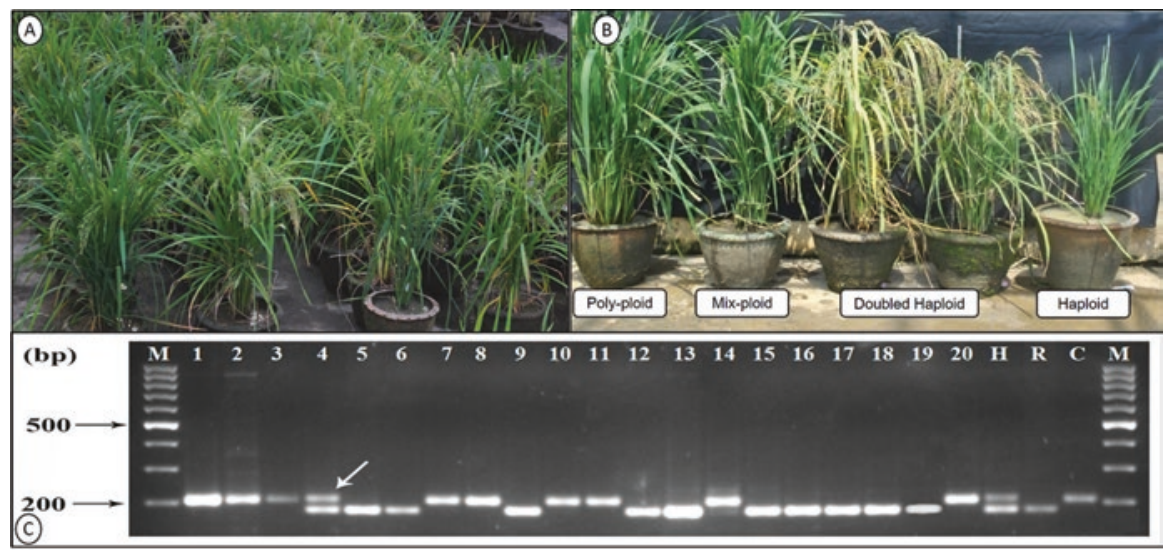

Fig. 2 Ploidy status in green regenerants. (a) $\mathrm{A}_{0}$ plants grown in net house; (b) morphological discrimination of ploidy status; (c) SSR marker (RM480) differentiating somatic tissue-derived heterozygotes from DHs. $\mathrm{M}=100$-bp DNA ladder; $\mathrm{C}=\mathrm{CRMS31A}$; $\mathrm{R}=\mathrm{CRL} 22 \mathrm{R} ; \mathrm{H}=\mathrm{CRHR} 32$; $1-3$ to $5-20=$ DHs; 4 = heterozygote (arrow)

Variations in nuclear DNA content of cultured plant tissues resulted in changes in ploidy level, which in turn changes the phenotypic characters of the regenerants, termed as triploid, tetraploid, polyploid, and aneuploid. This kind of variability occurred especially in chromosome number variations of regenerated plants, that is, ploidy changes: deletion, duplication, and rearrangements (d'Amato 1989). The chromosome aberrations influenced agronomic traits and the ploidy level of rice plants (Zhang and Chu 1984). Since the isolated anthers sometimes become contaminated from the anther wall tissues, the developed calli may be of mixed type such as haploid, diploid, triploid, and tetraploid (Dunwell 2010).

Different ploidy status can be evaluated through several approaches.

\subsection{Morphological}

Fertile diploids can be well-distinguished from other ploids such as haploids, triploids, and polyploids through morphological evaluation (Fig. 2b). The diploids or putative DHs show normal morphological appearance with 70-80\% grain fertility, whereas the polyploids are tall, large, and possess broad thick leaves with less than $1 \%$ spikelet fertility. Short stature with no spikelet fertility confirms haploids. Sometimes, mixploids are observed in the regenerants, which can be discriminated by observing grain type after grain maturity (Fig. 2b). 


\subsection{Cytological}

Of the several methods tested earlier, the classical cytological approach was thought to be ideal to determine ploidy status. Ploidy status in plants can be determined by counting the chromosomes of root tip cells arrested in metaphase stage (Mishra et al. 2015). However, this approach is tedious and time-consuming and also requires expertise. This is also considered an unambiguous method. Most importantly, tissues containing dividing cells may not always be readily available for analysis.

\subsection{Pollen Fertility Analysis}

Stomatal density and size, the size of pollen grains, cell size, and plant size are mainly considered to analyze the ploidy level in DHs, out of which a cytologybased approach through pollen size determination was used as an alternative, convenient, rapid, and reliable method to assess the ploidy level in several plant species (Zonneveld and Van Iren 2001). This method also has its own demerits like cytology.

\subsection{Flow Cytometry}

Since the nuclear DNA content and the ploidy level have close association, flow cytometry is the most reliable method and it has wide application in plant-ploidy analysis (Ochatt 2008; Cousin et al. 2009; X Wang et al. 2016). It is frequently used to analyze the ploidy level of individuals obtained from experiments of haplodiploidization or chromosome doubling (Grewal et al. 2009; Ochatt et al. 2009). This method was used to discriminate the ploidy status of the regenerants developed from rice hybrids (Mishra et al. 2015).

\subsection{High-Throughput Cell Analysis}

Most recently, a quick and precise ploidy determination method was developed using high-throughput cell analysis (Sahoo et al. 2019). This is useful to analyze nuclear DNA content-based ploidy validation of a large number of samples.

None of these approaches could differentiate DHs from heterozygotes (somatic tissue-derived diploids), for which molecular markers might be the best option for the identification of true DHs (Rout et al. 2016; Naik et al. 2017). 


\subsection{Molecular Markers}

Genomic molecular markers are highly heritable, available in high numbers, and often exhibit enough polymorphism to discriminate closely related genotypes. Simple sequence repeats (SSRs) are abundant and well-distributed throughout the rice genome. They are the most commonly used markers for understanding the source of origin (originated from the microspore mother cells or embryogenesis from diploid somatic tissue), parental contribution (allelic frequencies), and homozygosity in plant derivatives. SSRs have been successfully used to identify homozygous spontaneous-doubled haploids in rice hybrids (Fig. 2c).

\section{Application of DHs in Rice Improvement}

To meet the challenge of food security for the increasing population amid diminishing resources such as cultivable land and irrigation water along with climate change associated with unpredictable and unseasonal weather patterns, the development of high-yielding rice varieties is required to feed the ever-growing population. Hybrid rice is considered as a best option to break through the yield barrier, showing significant yield advantages over conventional cultivars. Although hybrid rice can outyield conventional cultivars by $30-40 \%$ in production fields, it does not gain in popularity among Indian farmers because of its complicated seed production system, purchase of nonreplaceable seed every season (as it segregates in consequent seasons), higher seed cost, less-preferred quality, and vulnerability to abiotic and biotic stresses. Therefore, we need to find an alternative way to exploit hybrid potential in fixing heterosis along with the associated problems for which DH technology was found to be efficient in the rapid fixation of favorable alleles for yield and related traits. The DH breeding technique shortens the time required for breeding a new variety from the usual $\sim 8$ to $\sim 5$ years, thus saving time, labor, and financial resources. Conversely, the DH technique could be more appropriate for developing new varieties from photosensitive rice genotypes. Most of these advances were achieved in japonica cultivars, which were amenable to anther culture, rather than in indica rice. Significantly, several varieties and improved parental lines have been developed through androgenic approaches, but restricted to only japonica rice cultivars. However, the use of anther culture as a routine technique for breeding is extremely limited in indica rice due to the poor induction of androgenic calli and subsequent plant regeneration. An efficient androgenic protocol could generate a considerable number of DHs for various applications. 


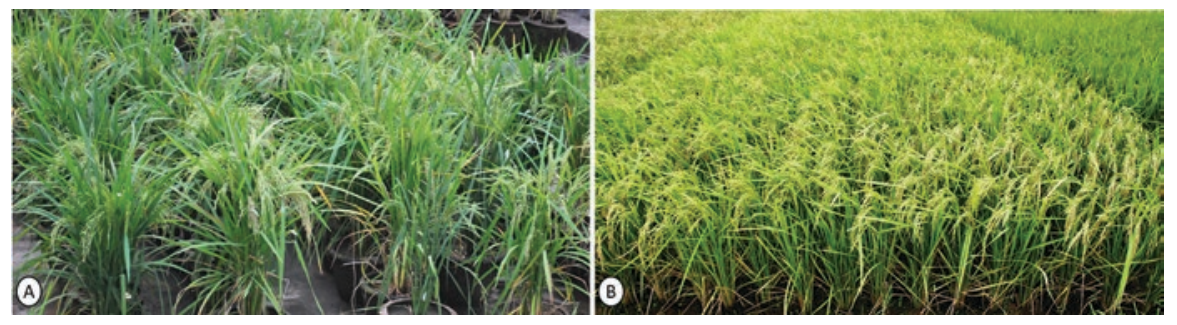

Fig. 3 Promising doubled haploids derived from rice hybrids (CRHR32 and BS6444G). (a) DHs of BS6444G showing yield equal to that of the parent; (b) grain quality of DH lines of hybrid BS6444G

\subsection{Performance of DHs Derived from Hybrid Rice}

The DH technique was used to overcome the constraints associated with indica rice hybrids: (1) expensive seed, depriving Indian marginal farmers from using the seed year after year; and (2) unpredictable environmental conditions and synchronized flowering. Standardization of DH technology in rice hybrids (PHB71 and KRH2) generated DHs from which two were released as varieties, Satyakrishna in 2008 and Phalguni in 2010. Subsequently, androgenic protocols in two more indica rice hybrids, CRHR32 (an elite long-duration indica rice hybrid developed at NRRI, Cuttack) and BS6444G (a popular rice hybrid, Bayer Seed Pvt. Ltd., Hyderabad), generated a considerable number of DHs (Rout et al. 2016; Naik et al. 2017). Some of the DHs showed grain yield on par with that of the parent rice hybrids (Fig. 3a); the grain quality of the DHs was also higher than that of the rice hybrids (Fig. 3b).

\subsection{Mapping of Genes and QTLs for Biotic and Abiotic Stress}

A quantitative trait locus (QTL) is the genomic region that contributes toward discrete traits, governed by multiple genes. In plant species, QTLs are the major determinants of important agronomic traits and mapping these genomic regions onto the specific chromosomal locations is vital for their application for crop improvement. Among the different mapping populations used for mapping QTLs in plants, doubled-haploid populations have their own significance. Since the effects of QTLs are small and are greatly influenced by environmental factors, this necessitates accurate phenotyping with replicated trials under different environmental conditions. Therefore, DH populations are among the few mapping populations with true breeding nature that can facilitate effective mapping of QTLs in plants. In addition, DH-mapping populations are developed in a short time, in one generation, as compared with other nonsegregating, true-breeding populations such as near-isogenic lines (NILs) and recombinant inbred lines (RILs). Therefore, DH populations are an effective and efficient source for mapping of genes and QTLs (Forster and Thomas 
2003; Forster et al. 2007). Subsequently, DH breeding through androgenesis has emerged as a potent tool and a suitable alternative to other techniques for crop improvement (Purwoko et al. 2010; Germana 2011).

A doubled-haploid population was used to map rice blast resistance genes and QTLs in a more efficient way (Z Wang et al. 2001). A DH population from a cross between blast-resistant variety Zhai Ye Qing 8 and susceptible variety Jin Xi17 was used in combination with cDNA-amplified fragment length polymorphism and bulked segregant analysis to identify rice blast resistance genes (Zheng et al. 2004). Subsequently, Fatah et al. (2014) used DH lines developed from IR64 and Azucena to map QTL regions having major blast resistance genes. A QTL responsible for rice blast disease resistance was also mapped using a combination of DH mapping population consisting of 88 lines (DH lines), derived by crossing Joiku No. 462 (a blast-resistant line) and Jokei06214 (a blast-susceptible line). Besides leaf blast, three main QTLs for neck blast resistance were identified and mapped onto rice chromosomes 10 ( $q N B L-10), 9$ ( $q N B L-9)$, and 5 ( $q N B L-5)$ using a DH population from a cross between IR64 and Azucena, and the DH lines displayed complete neck blast resistance under field conditions (Hittalmani et al. 2000).

Similarly, QTLs linked to resistance to another major rice disease, sheath blight, were identified in a DH population. Kunihiro et al. (2002) employed indica rice line Zhai Ye Qing 8 (ZYQ8) and japonica rice line Jing Xi 17 (JX17), along with their DH population, to identify four sheath blight resistance (ShBR) QTLs, qSBR-2, $q S B R-3, q S B R-7$, and $q S B R-11$, and mapped them on chromosomes 2, 3, 7, and 11, respectively. A DH population derived from japonica rice line Maybelle and indica rice line Baiyeqiu was also used to map a ShBR QTL using marker-assisted selection (MAS) (Xu et al. 2011). Zeng et al. (2015) developed a DH population by crossing japonica rice line CJ06 and indica line TN1, which underwent field evaluation under three different environmental conditions. They identified a total of eight QTLs each for lesion height (LH) and disease rating (DR) under three environments.

Besides for rice diseases, DH lines are used for mapping QTLs for insect resistance. Using DH lines developed by crossing IR64 and Azucena, six QTLs linked with brown planthopper $(\mathrm{BPH})$ resistance in rice were mapped (Soundararajan et al. 2004). Using the same DH population, Geethanjali et al. (2009) identified QTLs responsible for white-backed planthopper (WBPH) resistance. Later, a DH population obtained from a cross between Cheonhcheong and Nagdong was used to identify and map QTLs for WBPH resistance. Further, the $F_{1}$ rice line derived from a cross between JSNDH13 (BPH-resistant) and CNDH32 (WBPH-resistant) was used to develop a DH line having resistance to both insect pests (Yi et al. 2015).

Efforts are also made to map QTLs contributing to viral disease resistance in rice. Among two DH populations derived from crosses between IR64 and Azucena, and IRAT177 and Apura, the DH population derived from the former cross could map a QTL responsible for rice yellow mottle virus resistance to chromosome 12 of the rice genome (Ghesquière et al. 1997).

Further, anther culture was used to develop a mapping population from Savitri (a high-yielding indica rice variety) $\times$ Pokkali (a salt-tolerant indica rice genotype) for the identification of salt tolerance QTLs/genes. A systematic study with 117 DHs 


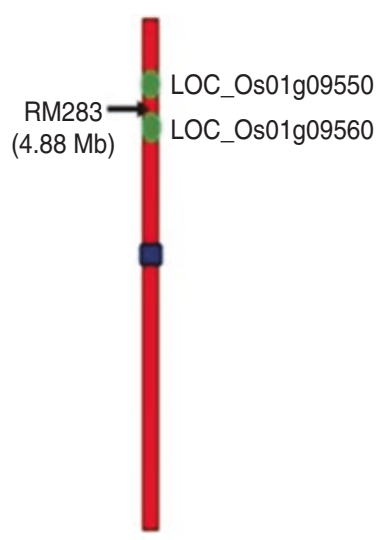

Ch \# 1

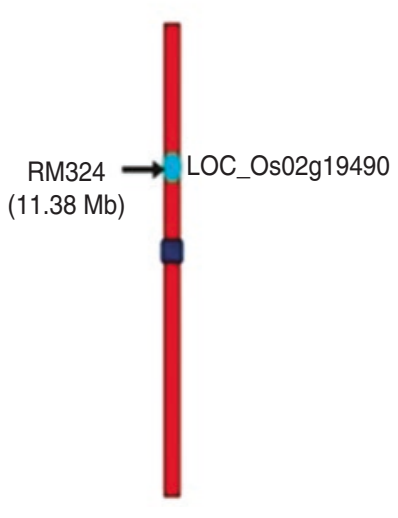

Ch \# 2

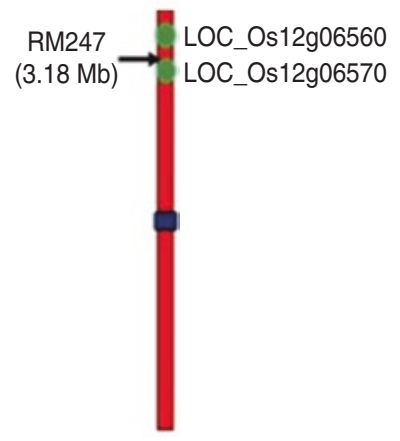

Ch \# 12

Fig. 4 Identified four candidate genes for salinity tolerance at germination stage using a doubledhaploid mapping population (Savitri $\times$ Pokkali)

derived from $\mathrm{F}_{1} \mathrm{~s}$ of Savitri and Pokkali (developed at ICAR-NRRI, Cuttack) was able to identify four candidate genes, LOC_Os01g09550 (no apical meristem protein), LOC_Os01g09560 (mitochondrial processing peptidase subunit alpha), LOC_Os12g06560 (putative protein), and LOC_Os12g06570 (cyclic nucleotidegated ion channel), for salinity tolerance at germination stage (Fig. 4).

\subsection{Development of Improved Lines and Rice Cultivars}

Anther culture technology is able to fix all segregating loci (100\%) in one generation (Purwoko et al. 2010) rather than eight to ten inbreeding generations with the conventional approach. Furthermore, it is able to maintain maximum genetic variance and heritability (Prigge et al. 2012), thus providing an opportunity to select transgressive segregants/superior genotypes at a very early stage. Anther culture provides high reproducibility for early-selection results, which is efficient in trait improvement strategies with simplified steps (Dicu and Cristea 2016). Hence, it is found to be an economically viable option for accelerating breeding with more selection accuracy and breeding value (Rober et al. 2005).

Given the scenario of dynamic demographics and diversified quality preferences, breeding varieties combined for higher yield, more enhanced quality traits, and wider acceptability are major concerns. Grain quality in rice hybrids is found to be a major limitation in hybridization of rice area in India (Babu et al. 2013). Using genetically diverse parental lines with similar quality parameters are found to be a workable strategy to address quality concerns in hybrids. The DH approach in turn is a probable means of helping to overcome quality problems in hybrids as it is quite efficient in developing transgressive segregants with superior quality that might be 
useful as parents for hybrid rice research and for cultivar release. Several varieties and improved parental lines have been developed and exploited for cultivar development, mostly with a japonica genetic background (Grewal et al. 2011). This technology is observed to be useful in creating immortalized genetic units from genetic resources to make them amenable to crop improvement. The libraries of DH lines help in making genetic resources accessible to crop improvement by linking molecular inventories of gene banks with meaningful phenotypes. Thus, a decrease in the breeding cycle per se in varietal development has substantial economic impact on rice breeding by saving developmental costs and maximizing genetic gain in a short span of time in a more precise way.

Doubled haploids have been released for commercialization in several crops, including rice. In addition, DHs are used as parents in developing rice hybrids (Mishra and Rao 2016). In rice, more than 100 rice breeding lines or varieties have been developed and released in China, India, Japan, South Korea, Hungary, and the United States (Siddique 2015).

Rice varieties such as Huayu I, Huayu II, Xin Xiu, Late Keng 959, Tunghua 1, Tunghua 2, Tunghua 3, Zhonghua 8, Zhonghua 9, Huahanzao, Huajian 7902, Tanghuo 2, Shanhua 7706, and Huahanzao 77001 are high-yielding varieties with superior grain quality and resistance to blast and bacterial blight diseases (Zhang 1989; Hu and Zeng 1984; Chen et al. 1986). Nanhua 5, Noll, Hua 03, and Guan 18 have early maturity, good quality, and disease resistance (Zhu and Pan 1990). Huayu 15 is resistant to lodging and diseases and has good quality (Shouyi and Shouyin 1991). Milyang 90 has good-grain quality and is resistant to brown planthopper and stripe virus disease (Chung 1987). Hwacheongbyeo, Joryeongbyeo, and Hwajinbyeo are resistant to $\mathrm{BPH}$, rice stripe tenui-virus, blast, and bacterial blight (Lee et al. 1988). Bicoll (IR51500AC11-1) has salt tolerance (Senadhira et al. 2002) in China, South Korea, and the Philippines. Salinity-tolerant DH line AC-1 was developed at IRRI, Philippines, and is commercialized for salinity-prone areas of Bangladesh (Thomson et al. 2010). Table 1 lists the commercialized DH rice varieties.

In India, the National Rice Research Institute (NRRI), Cuttack, began DH work during 1997 to overcome the constraints associated with indica rice hybrids, that is, expensive seed, which led to preventing marginal farmers from using the seed over the years, and unpredictable environmental conditions. NRRI released two DH varieties, Satyakrishna (CR Dhan 10) in 2008 and Phalguni (CR Dhan 801) in 2010. In addition, rice variety Parag 401 (Patil et al. 1997) was also bred through DH breeding.

\subsection{Biofortification of Rice for Essential Traits}

Being a premier food crop, rice serves as the major source of energy, protein, thiamine, riboflavin, niacin, and micronutrients $(\mathrm{Fe}, \mathrm{Zn}, \mathrm{Ca})$ in the diet (Juliano 1997). However, owing to deficiency for essential micronutrients ("hidden hunger"), it is unable to address the nutritional food security of the country. Among 
Table 1 Rice doubled haploids commercialized in different countries

\begin{tabular}{|c|c|c|}
\hline Country & Name of DH & Important features \\
\hline \multirow[t]{2}{*}{ India } & Satyakrishna (CR Dhan 10) & \multirow{2}{*}{$\begin{array}{l}\text { High yield, higher } \\
\text { quality }\end{array}$} \\
\hline & Phalguni (CR Dhan 801) & \\
\hline China & $\begin{array}{l}\text { Huayu I, Huayu II, Xin Xiu, Late Keng 959, Tunghua 1, } \\
\text { Tunghua 2, Tunghua 3, Zhonghua 8, Zhonghua 9, } \\
\text { Huahanzao, Huajian 7902, Tanghuo 2, Shanhua 7706, } \\
\text { Huahanzao 77001, Tanfeng 1, Huayu III, Ta Be 78, } \\
\text { Guan } 18\end{array}$ & $\begin{array}{l}\text { High yield, superior } \\
\text { grain quality, resistance } \\
\text { to blast and bacterial } \\
\text { blight diseases }\end{array}$ \\
\hline $\begin{array}{l}\text { South } \\
\text { Korea }\end{array}$ & Nanhua 5, Noll, Hua 03, Guan 18 & $\begin{array}{l}\text { Early maturity, good } \\
\text { quality, and disease } \\
\text { resistance }\end{array}$ \\
\hline Philippines & AC-1 & Salinity tolerance \\
\hline Japan & $\begin{array}{l}\text { Joiku N. 394, Hirohikari, Hirohonami AC No. } 1 \text {, } \\
\text { Kibinohana }\end{array}$ & $\begin{array}{l}\text { High yield, quality type, } \\
\text { cold resistance }\end{array}$ \\
\hline Argentina & Patei and Moccoi & High yield \\
\hline Hungary & Dama & High yield \\
\hline
\end{tabular}

the micronutrient malnutrition conditions, $\mathrm{Fe}$ and $\mathrm{Zn}$ deficiencies are of major concern not only because of their serious health consequences but also of the number of people affected worldwide. Hence, enriching rice grain with iron and zinc is likely to have tremendous health benefits for the rice-eating population. In addition, the presence of a substantial amount of phytate $(0.06-2.22 \%)$ in rice, which inhibits the absorption of $\mathrm{Fe}$ and $\mathrm{Zn}$, needs to be lowered (Liang et al. 2007). Hence, biofortification of rice varieties with enhanced content of protein, iron, and zinc and lower phytate would be an ideal goal. Biofortification is a promising food-based approach for helping to overcome micronutrient malnutrition. Significant efforts have been made over the past decade to biofortify the major cereals targeted to different parts of the world and a lot of progress has already been achieved in this endeavor. There are two distinct ways in which the nutritional value of cereals can be enhanced. The first is by using the genetic variation available through breeding or genetic engineering. Another promising approach is the doubled-haploid method, in which fixed genetic materials can be developed faster relative to other mapping populations and can be evaluated across years and locations readily. This method has less-genetic background noise than in traditional breeding methods, which makes it an important genetic resource for mapping QTLs/genes for various traits related to biofortification. Several reports have shown the utility of DH populations in identifying QTLs for the concentration of micronutrients in rice grain. Recently, two DH populations developed by IRRI were evaluated to map the QTLs related to agronomic traits and grain micronutrients (Swamy et al. 2018). Considerable genetic variation has been observed for all traits in these $\mathrm{DH}$ populations. These kinds of $\mathrm{DH}$ lines can be used as donors in breeding programs or can be directly tested in multilocation trials to further evaluate their performance. 


\subsection{Exchange of Cytoplasmic and Nuclear Genomes}

In Arabidopsis, both maternal and paternal haploids containing wild-type chromosomes and maternal cytoplasm can be generated using CENH3-mediated haploid inducers as the male or female parent. Ravi et al. (2010) developed a CENH3-1 GFP-tailswap haploid inducer with Ler cytoplasm: Ler-cytoplasmic haploid inducer (HI). When pollinating Ler-cytoplasmic HI with pollen from a wild type with Col-0 cytoplasm or Col-0 WT, haploids with Col-0 WT chromosomes and Ler cytoplasm are generated. This method can be used to develop any combination of cytoplasmic and nuclear genomes by transferring the male nuclear genome into a heterologous cytoplasm rapidly and conveniently. This facilitates the production of new cytoplasmic male sterile (CMS) lines for $\mathrm{F}_{1}$ hybrid seed production. If the haploid inducer line has a CMS background, pollinating this HI line with different inbred lines generates paternal haploids, which carry CMS. One or a few paternal haploids need to be pollinated with pollen from the maternal inbred to produce a new diploid CMS line. Using paternal haploids for cytoplasmic conversions have three distinct advantages: (1) only two generations are needed, (2) the new CMS line has $100 \%$ of the genomes of either of the inbred lines, and (3) chromosome doubling is not required (Weber 2014). This method has been employed in maize using the ig 1 system for quite a while (Evans 2007). Most recently, knocking out the MATL ortholog in rice resulted in haploid induction at a rate of 2-6\%, suggesting the functional conservation of MATL, and this represents an advance for rice breeding (Yao et al. 2018).

\subsection{Reverse Breeding}

Hybrid seed is traditionally produced from a cross between two inbred lines. Dirks et al. (2009) proposed a novel plant breeding technology, reverse breeding, which can directly generate parental inbred lines from any hybrid. Three steps are required for reverse breeding: (1) inhibition of meiotic crossover in $F_{1}$ plants to produce gametes containing combinations of nonrecombinant parental chromosomes, (2) generation of DH lines via in vitro unfertilized ovule or anther culture, and (3) regeneration of the original hybrid through crossing DH lines with complementary sets of parental chromosomes.

\subsection{Gene Stacking from Biparental Crosses}

Introgression of one or a limited number of genes into elite inbreds by markerassisted backcrossing is routine in plant breeding (Lübberstedt and Frei 2012). At the end of backcross programs, a heterozygous plant is selfed to produce a fixed line. For single-gene introgression, the expected probability of individuals with the 
desired homozygous genotype is $1 / 4$. The frequency of expected genotypes decreases exponentially following the formula $1 / 4^{(n)}$, where $n$ is the number of independently segregating genes (Lübberstedt and Frei 2012; Ravi et al. 2010; Shen et al. 2015). In contrast, haploid target genotypes are generated with a frequency of $1 / 2^{(n)}$. For example, for five loci, the frequency of the desired homozygous genotype is $1 / 1024$ in selfed diploid progenies and 1/32 in haploid progenies. The application of doubled haploids thus significantly decreases the population size required to find desirable genotypes.

\subsection{Accelerating Plant Breeding by MAS and GS}

The availability of cheap and abundant molecular markers allows breeders to apply marker-assisted selection (MAS) and genomic selection (GS) in crop improvement. MAS depends on the identification of markers significantly associated with a trait. MAS allows breeders to discard a large number of plants with undesired gene combinations, pyramid beneficial genes in subsequent generations, minimize field testing, and decrease the number of generations (Collard and Mackill 2008; Dwivedi et al. 2015). The combination of MAS and DHs offers new opportunities for increasing genetic gain and shortens the time required for cultivar breeding. MAS and DHs have been successfully used to accelerate resistance breeding in cereal crops (Wessels and Botes 2014), which demonstrates the integration of MAS and DH technology to increase the speed of cultivar development vis-à-vis conventional breeding processes.

\subsection{Transgenic Research}

In general, the DH technique offers a rapid homozygous state attainment of heterologous loci. This principle can be used in transgenic research for developing homozygous plants within one generation. The selfing of transgenic plants after regeneration is usually the methodology followed to obtain homozygous plants for the transgenic loci. However, this requires two generations of selfing from positivetransformed plants for phenotypic validation. In contrast, anther culture of positivetransformed plants in T1 will result in homozygous conditions with one generation of selfing. Figure 5 gives a schematic representation of the segregation of the transgenic loci. Anther culture was successfully used for developing homozygous transgenic rice with the chitinase gene for enhanced sheath blight resistance (Baisakh et al. 2001). Further employment of anther culture could generate DHs from transgenics-containing genes involved in $\beta$-carotene metabolism (Datta et al. 2014). 


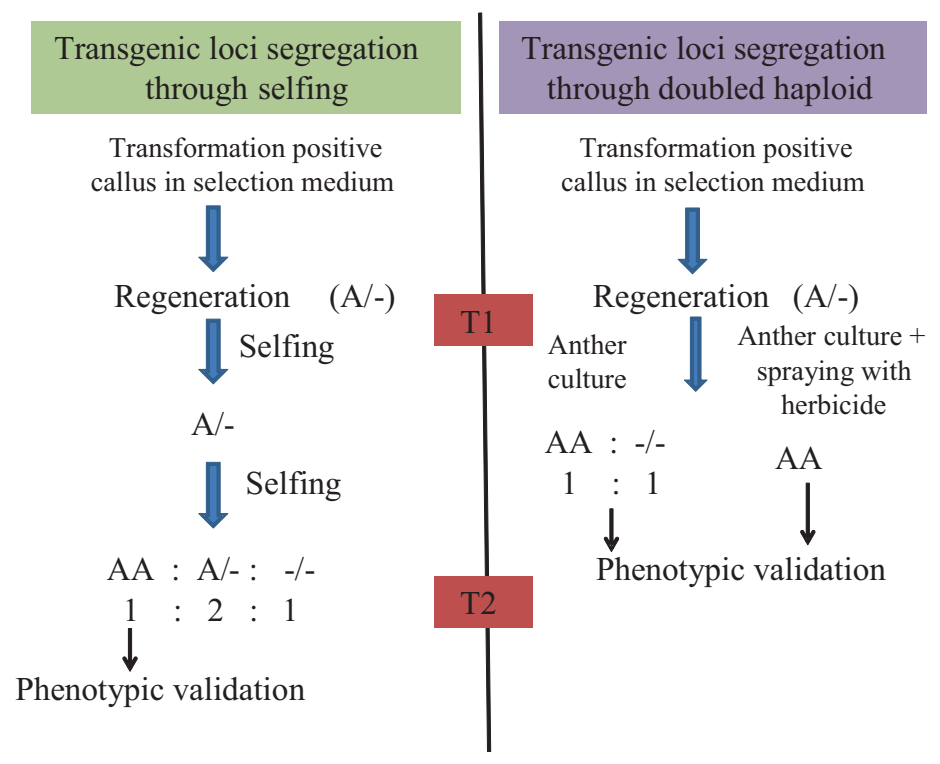

Fig. 5 Segregation of transgenic loci in selfed plants and anther culture plants

\section{Knowledge Gaps}

The recalcitrant nature of indica rice requires optimization of the anther culture method, which is essential to achieve the potential yield of androgenesis technology in indica rice lines. In spite of attempts made by Rout et al. (2016) and Naik et al. (2017) with these concerns, additional novel attempts for media manipulation have to be made to increase callusing potential or somatic embryogenesis. In addition, the identification of genomic regions that contribute to promising yield in rice from heterotic $\mathrm{F}_{1}$ hybrids has to be addressed by analyzing the genetic structure of DHs. Recent studies with Arabidopsis and maize (D Wang et al. 2015) suggest that heterosis could be fixed by carefully combining genomic regions from the parents that contribute to higher performance.

\section{The Way Forward}

Given the importance of DHs in the quick fixation of segregating loci and varietal development, we need to develop novel media composition to increase the callusing potential of anthers from indica rice. Simultaneously, we need to focus on direct somatic embryogenesis from microspores as this method is considered cost-effective among all the pathways in tissue culture. Moreover, the mechanism of spontaneous chromosome doubling in androgenesis requires immediate attention. Conceptual 
understanding of the superior yield of DHs is still not clear. Thus, the scientific basis of superior yield of DHs needs to be comprehensively studied through the generation of a large number of DHs ( 200 DHs from each hybrid).

Acknowledgments The authors acknowledge the director general of ICAR for continuous guidance and support for the research on doubled haploids at NRRI, Cuttack. We also greatly acknowledge the director of NRRI for his kind support and approval for bringing out a chapter on doubled haploids.

\section{References}

Asaduzzaman M, Bari MA, Rahman MH, Khatun N, Islam MA, Rahman M (2003) In vitro plant regeneration through anther culture of five rice varieties. J Biol Sci 3(2):167-171

Babu VR, Shreya K, Dangi KS, Usharani G, Nagesh P (2013) Evaluation of popular rice (Oryza sativa L.) hybrids for quantitative, qualitative and nutritional aspects. Int J Sci Res Publ 3(1):1

Baisakh N, Datta K, Oliva N, Ona I, Rao GJN, Mew TW, Datta SK (2001) Rapid development of homozygous transgenic rice using anther culture-harboring rice chitinase gene for enhanced sheath blight resistance. Plant Biotechnol 18(2):101-108

Ball ST, Zhou H, Konzak CF (1993) Influence of 2,4-D, IAA, and duration of callus induction in anther cultures of spring wheat. Plant Sci 90(2):195-200

Bjørnstad A, Opsahl-Ferstad HG, Aasmo M (1989) Effects of donor plant environment and light during incubation of anther cultures of some spring wheat (Triticum aestivum L.) cultivars. Plant Cell Tissue Organ Cult 17:27-37

Blakeslee AF, Belling J, Farnham ME, Bergner AD (1922) A haploid mutant in the jimson weed, "Daturastramonium". Science 55(1433):646-647

Chalyk ST (1994) Properties of maternal haploid maize plants and potential application to maize breeding. Euphytica 79:13-18

Chen JJ, Hus YJ, Tsay HS (1986) Effect of iron on rice anther culture. J Agric Res China 35(3):244-252

Chung GS (1987) Application of anther culture technique for rice (Oryza sativa L.) improvement. In: Korea-China Plant Tissue Culture Symposium. Academia Sinica Publishers, Beijing, pp 36-56

Collard BC, Mackill DJ (2008) Marker-assisted selection: an approach for precision plant breeding in the twenty-first century. Philos Trans R Soc Lond Biol 363:557-572

Cousin A, Heel K, Cowling WA, Nelson MN (2009) An efficient high-throughput flow cytometric method for estimating DNA ploidy level in plants. Cytom Part A 75(12):1015-1019

d'Amato F (1989) Polyploidy in cell differentiation. Caryologia 42:183-211

Datta K, Sahoo G, Krishnan S, Ganguly M, Datta SK (2014) Genetic stability developed for $\beta$-carotene synthesis in BR29 rice line using dihaploid homozygosity. PLoS One 9(6):e100212

Devaux P, Pickering R (2005) Haploids in the improvement of Poaceae. In: Palmer CE, Keller WA, Kasha KJ (eds) Haploids in crop improvement II. Biotechnology in agriculture and forestry, vol 56. Springer, Berlin; New York, NY, pp 215-242

Dicu G, Cristea S (2016) The efficiency use of doubled-haploid technology in maize breeding: obtaining DH parent lines and hybrids. Sci Pap Ser A Agron 59:273-278

Dirks R, Van Dun K, De Snoo CB, Van Den Berg M, Lelivelt CL, Voermans W, Woudenberg L, De Wit JP, Reinink K, Schut JW, Van Der Zeeuw E (2009) Reverse breeding: a novel breeding approach based on engineered meiosis. Plant Biotechnol J 7(9):837-845

Dunwell JM (2010) Haploids in flowering plants: origins and exploitation. Plant Biotechnol J 8:377-424 
Dwivedi SL, Britt AB, Tripathi L, Sharma S, Upadhyaya HD, Ortiz R (2015) Haploids: constraints and opportunities in plant breeding. Biotechnol Adv 33:812-829

Evans MM (2007) The indeterminate gametophyte 1 gene of maize encodes a LOB domain protein required for embryo sac and leaf development. Plant Cell 19(1):46-62

Fatah T, Rafii MY, Rahim HA, Meon S, Azhar M, Latif MA (2014) Cloning and analysis of QTL linked to blast disease resistance in Malaysian rice variety PongsuSeribu 2. Int J Agric Biol 16:395-400

Forster BP, Thomas WTB (2003) Doubled haploids in genetic mapping and genomics. In: Doubled haploid production in crop plants. Springer, Dordrecht, pp 367-390

Forster BP, Heberle-Bors E, Kasha KJ, Touraev A (2007) The resurgence of haploids in higher plants. Trends Plant Sci 12(8):368-375

Geethanjali S, Kadirvel P, Gunathilagaraj K, Maheswaran M (2009) Detection of quantitative trait loci (QTL) associated with resistance to white-backed planthopper (Sogatella furcifera) in rice (Oryza sativa). Plant Breed 128:130-136

Germana MA (2011) Anther culture for haploid and doubled haploid production. Plant Cell Tissue Organ Cult 104(3):283-300

Ghesquière A, Albar L, Lorieux M, Ahmadi N, Fargette D, Huang N, McCouch SR, Nottéghem JL (1997) A major quantitative trait locus for rice yellow mottle virus resistance maps to a cluster of blast resistance genes on chromosome 12. Phytopathology 87(12):1243-1249

Grewal D, Gill R, Gosal SS (2006) Role of cysteine in enhancing androgenesis and regeneration of indica rice (Oryza sativa L.). Plant Growth Regul 49(1):43-47

Grewal RK, Lulsdorf M, Croser J, Ochatt S, Vandenberg A, Warkenti TD (2009) Doubled haploid production in chickpea (Cicer arietinum L.): role of stress treatments. Plant Cell Rep 28:1289-1299

Grewal D, Manito C, Bartolome V (2011) Doubled haploids generated through anther culture from crosses of elite indica and japonica cultivars and/or lines of rice: large-scale production, agronomic performance, and molecular characterization. Crop Sci 51(6):2544-2553. https:// doi.org/10.2135/cropsci2011.04.0236

Grimes HD, Hodges TK (1990) The inorganic $\mathrm{NO}_{3}^{-}: \mathrm{NH}_{4}{ }^{+}$ratio influences plant regeneration and auxin sensitivity in primary callus derived from immature embryos of indica rice (Oryza sativa L.). J Plant Physiol 136:362-367

Guha S, Maheshwari SC (1964) In vitro production of embryos from anthers of Datura. Nature 204(4957):497

Guha S, Maheshwari SC (1966) Cell division and differentiation of embryos in the pollen grains of Datura in vitro. Nature 212:97-98

Häntzschel KR, Weber G (2010) Blockage of mitosis in maize root tips using colchicinealternatives. Protoplasma 241(1-4):99-104

Herath HMI, Bandara DC, Samarajeewa PK (2007) Effect of culture media for anther culture of indica rice varieties and hybrids of Indica and Japonica. Trop Agric Res Ext 10:17-22. https:// doi.org/10.4038/tare.v10i0.1866

Hittalmani S, Parco A, Mew TV, Zeigler RS, Huang N (2000) Fine-mapping and DNA markerassisted pyramiding of the three major genes for blast resistance in rice. Theor Appl Genet 100(7):1121-1128

Hu H, Zeng JZ (1984) Development of new varieties via anther culture. In: Ammirato PV, Evans DA, Sharp WR et al (eds) Handbook of plant cell culture, vol 3. Macmillan, New York, NY, pp 65-90

Ivanova M, Van Staden J (2009) Nitrogen source, concentration, and $\mathrm{NH}_{4}{ }^{+}: \mathrm{NO}_{3}{ }^{-}$ratio influence shoot regeneration and hyperhydricity in tissue-cultured Aloe polyphylla. Plant Cell Tissue Organ Cult 99(2):167-174

Jacquard C, Asakaviciute R, Hamalian AM, Sangwan RS, Devaux P, Clement C (2006) Barley anther culture: effects of annual cycle and spike position on microspore embryogenesis and albinism. Plant Cell Rep 25:375-381

Juliano BO (1997) Rice products in Asia. FAO-RAP publication No. 38. FAO, Rome 
Kleiber D, Prigge V, Melchinger AE, Burkard F, San Vicente F, Palomino G, Gordillo GA (2012) Haploid fertility in temperate and tropical maize germplasm. Crop Sci 52:623-630

Kunihiro Y, Qian Q, Sato H, Teng S, Zeng DL, Fujimoto K, Zhu LH (2002) QTL analysis of sheath blight resistance in rice (Oryza sativa L.). Chin J Genet 29:50-55

Lee SY, Lee YT, Lee MS (1988) Studies on the anther culture of Oryza sativa L. 3. Growing environment of donor plant in anther culture, effects of photoperiod and light intensity. Res Rep Rural Dev Adm Biotechnol 30:7-12

Liang J, Han B-Z, Han L, Robert Nout MJ, Hamer RJ (2007) Iron, zinc and phytic acid content of selected rice varieties from China. J Sci Food Agric 87:504-510

Lübberstedt T, Frei UK (2012) Application of doubled haploids for target gene fixation in backcross programmes of maize. Plant Breed 131(3):449-452

Melchinger AE, Molenaar WS, Mirdita V, Schipprack W (2016) Colchicine alternatives for chromosome doubling in maize haploids for doubled-haploid production. Crop Sci 56:559-569

Min ZY, Li H, Zou T, Tong L, Cheng J, Sun XW (2016) Studies of in vitro culture and plant regeneration of unfertilized ovary of pumpkin. Chin Bull Bot 51(1):74-80

Mishra R, Rao GJN (2016) In-vitro androgenesis in rice: advantages, constraints and future prospects. Rice Sci 23:57-68

Mishra R, Rao GJN, Rao RN (2013) Effect of cold pretreatment and phytohormones on anther culture efficiency of two indica rice (Oryza sativa L.) hybrids, Ajay and Rajalaxmi. J Exp Biol Agric Sci 1(2):69-76

Mishra R, Rao GJN, Rao RN, Kaushal P (2015) Development and characterization of elite-doubled haploid lines from two indica rice hybrids. Rice Sci 22(6):290-299

Murovec J, Bohanec B (2012) Haploids and doubled haploids in plant breeding. In: Abdurakhmonov I (ed) Plant breeding. InTech, Rijeka, pp 87-106

Naik N, Rout P, Umakanta N, Verma RL, Katara JL, Sahoo KK et al (2017) Development of doubled haploids from an elite indica rice hybrid (BS6444G) using anther culture. Plant Cell Tissue Organ Cult 128(3):679-689

Niizeki H, Oono K (1968) Induction of haploid rice plant from anther culture. Proc Jpn Acad 44(6):554-557

Nurhasanah, Pratama AN, Sunaryo W (2016) Anther culture of local upland rice varieties from East Kalimantan: effect of panicle cold pre-treatment and putrescine-enriched medium. Biodiversitas 17(1):148-153

Ochatt SJ (2008) Flow cytometry in plant breeding. Cytom Part A 73(7):581-598

Ochatt S, Pech C, Grewal R, Conreux C, Lulsdorf M, Jacas L (2009) Abiotic stress enhances androgenesis from isolated microspores of some legume species (Fabaceae). J Plant Physiol 166:1314-1328

Patil VD, Nerkar YS, Misal MB, Harkal SR (1997) Parag 401, a semidwarf rice variety developed through anther culture. Int Rice Res Notes 22(2):19

Prasanna BM, Chaikam V, Mahuku G (2012) Doubled haploid technology in maize breeding: theory and practice. International Maize and Wheat Improvement Center (CIMMYT), Mexico

Prigge V, Xu XW, Li L, Babu R, Chen SJ, Atlin GN, Melchinger AE (2012) New insights into the genetics of in vivo induction of maternal haploids, the backbone of doubled haploid technology in maize. Genetics 111:781-793

Purwoko BS, Dewi IS, Khumaida K (2010) Rice anther culture to obtain doubled-haploids with multiple tolerances. Asia Pac J Mol Biol Biotechnol 18(1):55-57

Ravi M, Kwong PN, Menorca RM, Valencia JT, Ramahi JS, Stewart JL, Tran RK et al (2010) The rapidly evolving centromere-specific histone has stringent functional requirements in Arabidopsis thaliana. Genetics 186:461-471

Rober FK, Gordillo GA, Geiger HH (2005) In vivo haploid induction in maize: performance of new inducers and significance of doubled haploid lines in hybrid breeding. Maydica 50:275-283

Rout P, Naik N, Ngangkham U, Verma RL, Katara JL, Singh ON, Samantaray S (2016) Doubled haploids generated through anther culture from an elite long-duration rice hybrid, CRHR32: method optimization and molecular characterization. Plant Biotechnol 33(3):177-186 
Sahoo SA, Jha Z, Verulkar SB, Srivastava AK, Suprasanna P (2019) High-throughput cell analysis based protocol for ploidy determination in anther-derived rice callus. Plant Cell Tissue Organ Cult 137(1):187-192

Seguí-Simarro JM, Nuez F (2008) How microspores transform into haploid embryos: changes associated with embryogenesis induction and microspore-derived embryogenesis. Physiol Plant 134:1-12

Senadhira D, Zapata-Arias FJ, Gregorio GB, Alejar MS, De La Cruz HC, Padolina TF, Galvez AM (2002) Development of the first salt-tolerant rice cultivar through indicalindica anther culture. Field Crop Res 76:103-110

Shen Y, Pan G, Lubberstedt T (2015) Haploid strategies for functional validation of plant genes. Trends Biotechnol 33:611-620

Shouyi L, Shouyin H (1991) Huayu 15, a high-yielding rice variety bred by anther culture. In: Bajaj YPS (ed) Biotechnology in agriculture and forestry, Volume 14: rice. Springer, Berlin; New York, NY, pp 230-247

Siddique R (2015) Impact of different media and genotypes in improving anther culture response in rice (Oryza sativa) in Bangladesh. Eur Sci J 11(6)

Soundararajan RP, Kadirvel P, Gunathilagaraj K, Maheswaran M (2004) Mapping of quantitative trait loci associated with resistance to brown plant hopper in rice by means of a doubled haploid population. Crop Sci 44:2214-2220

Swamy BM, Descalsota GIL, Nha CT, Amparado A, Inabangan-Asilo MA, Manito C et al (2018) Identification of genomic regions associated with agronomic and biofortification traits in DH populations of rice. PLoS One 13(8):e0201756

Talebi R, Rahemi MR, Arefi H, Nourozi M, Bagheri N (2007) In vitro plant regeneration through anther culture of some Iranian local rice (Oryza sativa L.) cultivars. Pak J Biol Sci 10(12):2056-2060

Thomson MJ, de Ocampo M, Egdane J, Rahman MA, Sajise AG, Adorada DL, Tumimbang-Raiz E, Blumwald E, Seraj ZI, Singh K, Gregorio GB, Ismail AM (2010) Characterizing the Saltol quantitative trait locus for salinity tolerance in rice. Rice 3(2):148-160

Trejo-Tapia G, Amaya UM, Morales GS, Sanchez ADJ, Bonfil BM, Rodriguez-Monroy M, JimenezAparicio A (2002) The effects of cold-pretreatment, auxins and carbon source on anther culture of rice. Plant Cell Tissue Organ Cult 71:41-46. https://doi.org/10.1023/A:1016558025840

Veeraraghavan R (2007) A study on the comparison of anther culture response in different varieties of rice (Oryza sativa L.) subspecies indica. University of Colombo, Colombo. PMCid: PMC1891355

Wan Y, Duncan DR, Rayburn AL, Petolino JF, Widholm JM (1991) The use of antimicrotubule herbicides for the production of doubled haploid plants from anther-derived maize callus. Theor Appl Genet 81:205-211

Wang Z, Taramino G, Yang D, Liu G, Tingey SV, Miao GH, Wang GL (2001) Rice ESTs with disease-resistance gene- or defense-response gene-like sequences mapped to regions containing major resistance genes or QTLs. Mol Gen Genomics 265(2):302-310

Wang D, Yu C, Zuo T, Zhang J, Weber DF, Peterson T (2015) Alternative transposition generates new chimeric genes and segmental duplications at the maize p1 locus. Genetics 201:925-935

Wang X, Cheng ZM, Zhi S, Xu F (2016) Breeding triploid plants: a review. Czech J Genet Plant Breed 52(2):41-54

Weber DF (2014) Today's use of haploids in corn plant breeding. Adv Agron 123:123-144

Wessels E, Botes WC (2014) Accelerating resistance breeding in wheat by integrating markerassisted selection and doubled haploid technology. S Afr J Plant Soil 31:35-43

Xu Q, Yuan XP, Yu HY, Wang YP, Tang SX, Wei XH (2011) Mapping quantitative trait loci for sheath blight resistance in rice using double haploid population. Plant Breed 130(3):404-406

Yamagishi M (2002) Heterogeneous plastid genomes in anther culture-derived albino rice plants. Euphytica 123(1):67-74

Yao L, Zhang Y, Liu C, Liu Y, Wang Y, Liang D, Liu J, Sahoo G, Kelliher T (2018) OsMATL mutation induces haploid seed formation in indica rice. Nat Plants 4:530-533 
Yi S, Wu G, Lin Y, Hu N, Liu Z (2015) Characterization of a new type of glyphosate-tolerant 5-enolpyruvyl shikimate-3-phosphate synthase from Isoptericolava riabilis. J Mol Catal B Enzym 111:1-8. https://doi.org/10.1016/j.molcatb.2014.11.009

Zeng YX, Xia LZ, Wen ZH, Ji ZJ, Zeng DL, Qian Q, Yang CD (2015) Mapping-resistant QTLs for rice sheath blight disease with a doubled haploid population. J Integr Agric 14(5):801-810

Zhang ZH (1989) The practicability of anther culture breeding in rice. In: Advances in plant biotechnology. CIMMYT, IRRI, Mexico, Los Baños, pp 36-37

Zhang LN, Chu QR (1984) Characteristic and chromosomal variation of somaclones and its progeny in rice (Oryza sativa L.). Sci Agric Sin (China) (4):14

Zheng X, Chen X, Zhang X, Lin Z, Shang J, Xu J, Zhai W, Zhu L (2004) Isolation and identification of a gene in response to rice blast disease in rice. Plant Mol Biol 54(1):99-109

Zhu DY, Pan XG (1990) Rice (Oryza sativa L.): guan 18: an improved variety through anther culture. In: Bajaj YPS (ed) Biotechnology in agriculture and forestry 12: rice. Springer, Berlin, pp 204-211

Zonneveld BJM, Van Iren F (2001) Genome size and pollen viability as taxonomic criteria, application to the genus Hosta. Plant Biol 3:176-185

Open Access This chapter is licensed under the terms of the Creative Commons Attribution 4.0 International License (http://creativecommons.org/licenses/by/4.0/), which permits use, sharing, adaptation, distribution and reproduction in any medium or format, as long as you give appropriate credit to the original author(s) and the source, provide a link to the Creative Commons license and indicate if changes were made.

The images or other third party material in this chapter are included in the chapter's Creative Commons license, unless indicated otherwise in a credit line to the material. If material is not included in the chapter's Creative Commons license and your intended use is not permitted by statutory regulation or exceeds the permitted use, you will need to obtain permission directly from the copyright holder.

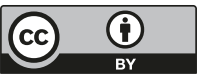

